\title{
Immunohistochemical Colocalization of Glycoxidation Products and Lipid Peroxidation Products in Diabetic Renal Glomerular Lesions Implication for Glycoxidative Stress in the Pathogenesis of Diabetic Nephropathy
}

\author{
Katsunori Horie, ${ }^{*}$ Toshio Miyata, ${ }^{\ddagger}$ Kenji Maeda, ${ }^{*}$ Satoshi Miyata, ${ }^{\S}$ Satoshi Sugiyama, ${ }^{\|}$Hideto Sakai, ${ }^{\ddagger}$ \\ Charles van Ypersele de Strihou, " Vincent M. Monnier, ${ }^{\star \star}$ Joseph L. Witztum, ${ }^{\ddagger \neq}$ and Kiyoshi Kurokawa ${ }^{\ddagger}$ \\ *Department of Internal Medicine, Nagoya University School of Medicine, Nagoya 461, Japan; ${ }^{\ddagger}$ Institute of Medical Sciences and \\ Department of Medicine, Tokai University School of Medicine, Isehara 259-11, Japan; ${ }^{\S}$ Department of Internal Medicine, Kobe University \\ School of Medicine, Kobe 650, Japan; "Chukyo Hospital, Nagoya 457, Japan; "Service de Nephrologie, Université Catholique de Louvain, \\ Brussels 1200, Belgium; **Institute of Pathology, Case Western Reserve University, Cleveland, Ohio 44106; and ${ }^{\ddagger}$ Department of \\ Endocrinology and Metabolism, University of California San Diego, San Diego, California 92093
}

\begin{abstract}
Advanced glycation end products (AGEs) include a variety of protein adducts whose accumulation alters the structure and function of tissue proteins and stimulates cellular responses. They have been implicated in tissue damage associated with diabetic complications. To assess the possible link between AGE accumulation and the development of diabetic nephropathy (DN), we have examined the immunohistochemical localization of various AGE structures postulated to date, i.e., pentosidine, $N^{\epsilon}$-(carboxymethyl)lysine (CML), and pyrraline, in diabetic and control kidneys. CML and pentosidine accumulate in the expanded mesangial matrix and thickened glomerular capillary walls of early DN and in nodular lesions and arterial walls of advanced DN, but were absent in control kidneys. By contrast, pyrraline was not found within diabetic glomeruli but was detected in the interstitial connective tissue of both normal and diabetic kidneys. Although the distribution of pyrraline was topographically identical to type III collagen, distribution of pentosidine and CML was not specific for collagen type, suggesting that difference in matrix protein composition per se could not explain heterogeneous AGE localization. Since oxidation is linked closely to the formation of pentosidine and CML, we also immunostained malondialdehyde (MDA), a lipid peroxidation product whose formation is accelerated by oxidative stress, assuming that local oxidative stress may serve as a mechanism of pentosidine and CML accumulation. Consistent with our assumption, diabetic nodular lesions were stained positive for MDA. These findings show that AGE localization in DN varies according to AGE structure, and suggest that the colocalization of markers of glycoxidation (pentosidine and CML) with a marker of lipid peroxidation reflects a local oxidative stress in association
\end{abstract}

Address correspondence to Dr. Toshio Miyata, Institute of Medical Sciences and Department of Medicine, Tokai University School of Medicine, Bohseidai, Isehara, Kanagawa 259-11, Japan. Phone: 81463-93-1936; FAX: 81-463-93-1938.

Received for publication 14 March 1997 and accepted in revised form 16 October 1997.

J. Clin. Invest.

(C) The American Society for Clinical Investigation, Inc. 0021-9738/97/12/2995/10 \$2.00

Volume 100, Number 12, December 1997, 2995-3004

http://www.jci.org with the pathogenesis of diabetic glomerular lesions. Thus, glycoxidation markers may serve as useful biomarkers of oxidative damage in DN. (J. Clin. Invest. 1997. 100:29953004.) Key words: advanced glycation end products $\bullet$ pentosidine $\bullet$ carboxymethyllysine $\bullet$ malondialdehyde $\bullet$ local oxidative stress

\section{Introduction}

Diabetic nephropathy $(\mathrm{DN})^{1}$ has become one of the main causes of end-stage renal disease. The metabolic events responsible for its development are as yet incompletely understood. Poor glycemic control undoubtedly plays a significant role, as shown by both clinical (1) and pathological studies (2). Possible mediators of untoward effects of hyperglycemia include advanced glycation end products (AGEs) known to accumulate in diabetic subjects $(3,4)$. AGEs comprise a variety of molecular structures, such as $N^{\epsilon}$-(carboxymethyl)lysine (CML) (5), pentosidine (6), and pyrraline (7). They are generated by the Maillard reaction (8) through nonenzymatic glycation of protein amino groups, and through oxidation reaction (9-12), as indicated in Fig. 1.

AGE accumulation in the skin is correlated with the severity of diabetic complications (13-15). Several lines of evidence suggest that AGEs are involved in the development of glomerular lesions in diabetes $(15,16)$. AGE modification alters the structure and function of matrix tissue proteins $(3,17)$, and, more interestingly, AGE-modified proteins stimulate a variety of cellular responses (18-22) via specific cell-surface receptors $(23,24)$, including glomerular mesangial cells (25-27). Thus, AGEs stimulate fibronectin (25) and type IV collagen (26) synthesis in cultured human or mouse mesangial cells. Finally, aminoguanidine, an inhibitor of the Maillard reaction, given to streptozotocin-induced diabetic mice, reduces urinary albumin excretion as well as mesangial expansion in the glomeruli (28), a hallmark of DN.

This study was undertaken to investigate further the role of AGEs in DN. AGEs include various structures characterized by different formation mechanisms. We have used a variety of specific antisera to assess the accumulation of pentosidine, CML, pyrraline, and other AGE structures in diabetic and control

1. Abbreviations used in this paper: AGE, advanced glycation end product; CML, $N^{\epsilon}$-(carboxymethyl)lysine; DN, diabetic nephropathy; $\mathrm{KLH}$, keyhole limpet hemocyanin; MCNS, minimal change nephrotic syndrome; MDA, malondialdehyde; NIDDM, non-insulin-dependent diabetes mellitus. 


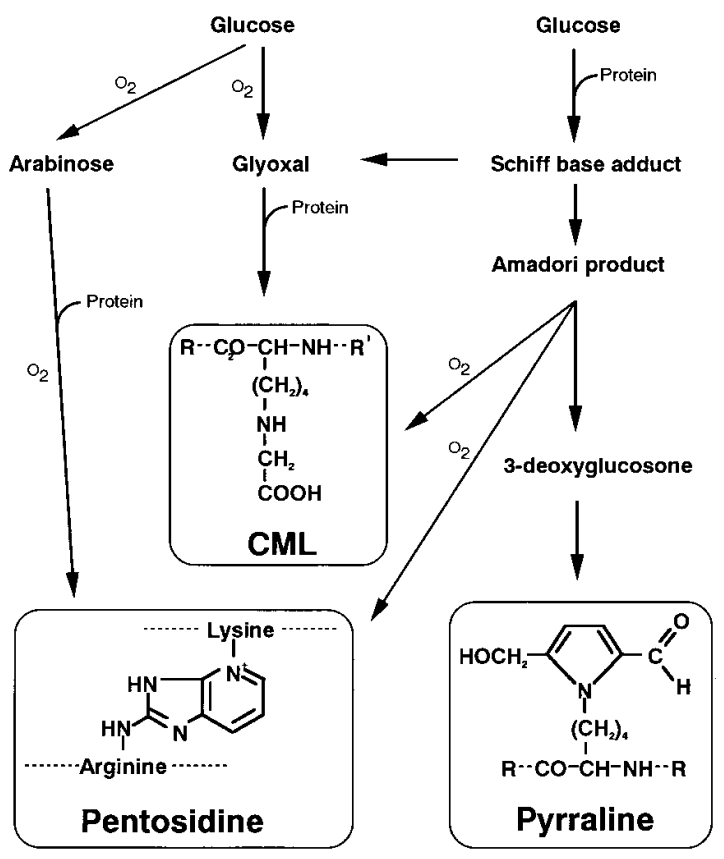

Figure 1. Maillard reaction pathway for formation of CML, pentosidine, and pyrraline. Fructoselysine is the Amadori compound, the first intermediate in the Maillard reaction occurring between glucose and protein. Pentosidine and CML are formed by sequential glycation and oxidation reactions (9). CML can form in two pathways: oxidative cleavage of fructoselysine (5), and reaction of protein with glyoxal, which is an autoxidation product of glucose or Schiff base adduct (10-12). Pentosidine is a cross-link between lysine and arginine residues resulting from glycoxidation of Amadori products or the reaction of arabinose, which is an autoxidative product of glucose $(10,11)$. Pyrraline is formed by the reaction of protein with 3-deoxyglucosone (47).

kidneys. As their distribution proved heterogeneous, it was compared with distribution of different collagen types and malondialdehyde (MDA), a lipid peroxidation product whose generation is accelerated by oxidative stress (29).

\section{Methods}

Specimens. Renal biopsy specimens were obtained with informed consent from 13 non-insulin-dependent diabetes mellitus (NIDDM) patients with DN, 3 patients with minimal change nephrotic syndrome (MCNS), and 3 patients with IgA nephropathy. The presence of DN was confirmed on renal biopsies by the presence of mesangial expansion (with Kimmelstiel-Wilson nodules in some patients) and the thickening of glomerular basement membrane (GBM) identified by light and electron microscopy, and by the linear staining pattern of IgG by immunofluorescence. Table I summarizes clinical data as well as pathological findings. In addition, renal tissue specimens were obtained at autopsy from four patients (two normal subjects, and two with NIDDM), all without any clinical or laboratory evidence of renal disease. Specimens fixed in $10 \%$ formalin and embedded in paraffin were cut at $5 \mu \mathrm{m}$. Sections were stained by periodic acid-Schiff reaction for light microscopy evaluation. Histological findings are summarized in Table I.

Antibodies. Antipentosidine rabbit antibody was produced by immunization of rabbits with keyhole limpet hemocyanin (KLH) modified with synthesized pentosidine. Pentosidine was synthesized by a method adapted from Grandhee and Monnier (30). A suspension of
$0.01 \mathrm{~mol}$ of $N^{\alpha}$-t-butoxycarbonyl-L-lysine and $0.08 \mathrm{~mol}$ of D-ribose in $100 \mathrm{ml}$ of methanol was stirred for $3 \mathrm{~h}$ at $30^{\circ} \mathrm{C}$. Methanol was evaporated under reduced pressure, resulting in a dark brown syrup. The residue was purified by column chromatography on Dowex $50 \mathrm{~W} \times 2$ (Aldrich Chemical Co., Milwaukee, WI) using a linear gradient from $0.2 \mathrm{M}$ (pH 3.1) to $2 \mathrm{M}$ (pH 5.0) pyridine acetate. The main fraction ( $N^{\alpha}$-t-butoxycarbonyl- $N^{\epsilon}$-[1-deoxy-D-ribulos-1-yl]-L-lysine) was collected, concentrated in vacuo, and lyophilized to give a partially purified product $(4.15 \mathrm{~g})$. The product thus obtained $(0.01 \mathrm{~mol})$ and $N^{\alpha}-$ $t$-butoxycarbonyl-L-arginine $(0.042 \mathrm{~mol})$ were dissolved in $100 \mathrm{ml}$ of sodium phosphate buffer ( $\mathrm{pH}$ 9.4). The $\mathrm{pH}$ of the solution was adjusted to 11-12 with $1 \mathrm{~N} \mathrm{NaOH}$. After stirring for $20 \mathrm{~h}$ at room temperature, the solution was acidified to $\mathrm{pH} 2$ with $6 \mathrm{~N} \mathrm{HCl}$ and concentrated in vacuo to give an oily residue. The $t$-butoxycarbonyl groups were removed by treatment with $300 \mathrm{ml}$ of trifluoroacetic acid for $1 \mathrm{~h}$ at room temperature. After removal of excess trifluoroacetic acid in vacuo, the residue was purified on HPLC using a reverse-phase column (YMC-Pack ODS; YMC Co., Ltd., Kyoto, Japan) to give a homogeneous product $(70 \mathrm{mg})$. The identity of the final product was confirmed as pentosidine by nuclear magnetic resonance and fast atom bombardment-mass spectrometry.

To prepare pentosidine-modified KLH, synthesized pentosidine was conjugated with KLH by our previous method (31). Briefly, $10 \mathrm{mg}$ of KLH (Pierce Chemical Co., Rockford, IL) was incubated with 7.5 $\mu \mathrm{mol}$ of pentosidine and $0.1 \mathrm{mmol}$ of 1-ethyl-3-(3-dimethylaminopropyl)carbodiimide- $\mathrm{HCl}$ (Pierce Chemical Co.) in the presence of $2.2 \mathrm{mg}$ of $N$-hydroxysulfosuccinimide (Pierce Chemical Co.) in $3 \mathrm{ml}$ of PBS for $4 \mathrm{~h}$ at room temperature, and then overnight at $4^{\circ} \mathrm{C}$. Pentosidine incorporation into $\mathrm{KLH}$ was $45.3 \mathrm{pmol} / \mu \mathrm{g}$, as determined by HPLC assay described previously $(31,32)$.

Pentosidine-modified KLH was used to immunize rabbits by standard procedures. IgG from immune serum was purified using a kit (Affi-Gel protein A MAPS II; Bio-Rad Laboratories, Richmond, CA). The resulting IgG fraction was affinity-purified further by adsorption to $\mathrm{CNBr}$-activated Sepharose 4B column (Pharmacia Biotech AB, Uppsala, Sweden) with immobilized BSA modified with pentosidine (5 $\mathrm{mg} / \mathrm{ml}$ gel), extensive washing with $20 \mathrm{mM}$ sodium phosphate buffer

Table I. Profiles of Patients Examined in This Study

\begin{tabular}{rrrrrrrr}
\hline Case & Age & Sex & Duration & Cr & BUN & HbA1c & Proteinuria \\
\hline & $y r$ & & $y r$ & $m g / d l$ & $m g / d l$ & $\%$ & $g / d$ \\
1 & 53 & M & 10 & 0.7 & 15 & 7.2 & 2.3 \\
2 & 51 & M & 10 & 0.7 & 15 & 7.6 & 0.2 \\
3 & 55 & M & 10 & 0.8 & 17 & 8.1 & 4.3 \\
4 & 55 & M & 20 & 0.8 & 18 & 9.3 & 0.3 \\
5 & 58 & M & 18 & 0.9 & 25 & 7.8 & 3.8 \\
6 & 63 & M & 2 & 1.1 & 21 & 6.8 & 3.2 \\
7 & 68 & M & 16 & 1.1 & 20 & 7.8 & 4.5 \\
8 & 61 & M & 10 & 1.4 & 22 & 8.4 & 4.8 \\
9 & 43 & M & 18 & 1.8 & 24 & 7.8 & 3.4 \\
10 & 61 & F & 22 & 2.4 & 46 & 8.6 & 3.8 \\
11 & 61 & M & 15 & 2.4 & 22 & 5.7 & 5.1 \\
12 & 46 & M & 23 & 4.8 & 56 & 12.6 & 7.1 \\
13 & 69 & M & 28 & 6.1 & 137 & 9.3 & 5.6 \\
14 & 18 & F & - & 0.7 & 15 & 4.9 & 0.7 \\
15 & 33 & M & - & 1.8 & 24 & 5.2 & 3.5 \\
16 & 60 & M & - & 1.2 & 16 & 5.1 & 0.5 \\
17 & 16 & F & - & 0.7 & 11 & 4.8 & 7.2 \\
18 & 18 & M & - & 0.9 & 12 & 4.7 & 6.4 \\
19 & 37 & M & - & 1.1 & 16 & 5.1 & 8.1 \\
& & & & & & & \\
\hline & & & & & & &
\end{tabular}

$C r$, Creatinine. BUN, Blood urea nitrogen. 
( $\mathrm{pH} 7.4$ ), and elution of bound immune $\mathrm{IgG}$ with the same buffer containing $3 \mathrm{M}$ potassium thiocyanate $(\mathrm{pH} 7.4)$. IgG was then dialyzed against $20 \mathrm{mM}$ sodium phosphate buffer ( $\mathrm{pH} 7.4)$.

Anti-AGE rabbit polyclonal IgG was raised by the immunization of rabbits with AGE-modified KLH, prepared by incubating $250 \mu \mathrm{g}$ of KLH with $1.67 \mathrm{M}$ D-glucose (Wako Pure Chemical Industries, Ltd., Osaka, Japan) at $37^{\circ} \mathrm{C}$ for $90 \mathrm{~d}$ in $1 \mathrm{ml}$ of $0.4 \mathrm{M}$ phosphate buffer ( $\mathrm{pH}$ 7.4). IgG from immune serum was purified on Affi-Gel protein A agarose, and affinity-purified further by adsorption to a CNBr-activated Sepharose 4B column with immobilized AGE-modified BSA ( $5 \mathrm{mg} / \mathrm{ml}$ gel) as described above.

Anti-AGE mouse monoclonal IgG (6D12; Wako Pure Chemical Industries, Ltd.) (33), antipyrraline mouse monoclonal IgG (34), antiMDA mouse monoclonal IgG $(35,36)$, and anticollagen type III, IV, $\mathrm{V}$, or VI goat polyclonal IgG (Southern Biotechnology Associates, Inc., Birmingham, AL) were also used.

Immunoblot analysis. The specificity of antibodies used in this study was assessed by Western blotting using BSA and BSA modified with Amadori products, the early Maillard products leading to AGEs, AGEs, pentosidine, CML, pyrraline, or MDA.

BSA modified with AGEs (AGE-BSA) or Amadori products (Amadori-BSA) was prepared by incubating $500 \mu \mathrm{g}$ of BSA (essentially fatty acid-free grade; Sigma Chemical Co., St. Louis, MO) with $0.1 \mathrm{M}$ D-glucose at $37^{\circ} \mathrm{C}$ for 60 or $10 \mathrm{~d}$ in $500 \mu \mathrm{l}$ of $0.1 \mathrm{M}$ phosphate buffer ( $\mathrm{pH}$ 7.4). The presence of AGEs in glycated BSA after a 60-d incubation has been demonstrated previously (37). The level of Amadori products (fructoselysine) in the glycated $\beta 2$-microglobulin after a 10 -d incubation was $0.44 \mathrm{~mol} / \mathrm{mol}$ of BSA, as determined by colorimetric assay (22) using a kit (Fructosamine Test Roche-II; Nihon Roche Ltd., Tokyo, Japan). BSA modified with pentosidine (pentosidine-BSA), CML (CML-BSA), pyrraline (pyrraline-BSA), or MDA (MDA-BSA), was prepared by conjugating BSA with synthesized pentosidine, CML, pyrraline, or MDA as described above.

Samples $(10 \mu \mathrm{g}$ each) thus prepared were separated by SDSPAGE using a 5-20\% gradient acrylamide gel. After electrophoretic transfer to a polyvinylidene difluoride membrane (Bio-Rad Laboratories), the membrane was first incubated overnight with $3 \%$ skim milk, and subsequently for $1 \mathrm{~h}$ at room temperature with anti-AGE mouse monoclonal $\operatorname{IgG}(10 \mu \mathrm{g} / \mathrm{ml})$, anti-AGE rabbit polyclonal $\mathrm{IgG}$ $(10 \mu \mathrm{g} / \mathrm{ml})$, antipentosidine rabbit $\operatorname{IgG}(2.0 \mu \mathrm{g} / \mathrm{ml})$, antipyrraline mouse monoclonal IgG $(10 \mu \mathrm{g} / \mathrm{ml})$, or anti-MDA mouse monoclonal IgG $(1.0 \mu \mathrm{g} / \mathrm{ml})$ in a buffer solution containing $25 \mathrm{mM}$ Tris- $\mathrm{HCl}(\mathrm{pH} 7.5)$ and $0.5 \mathrm{M} \mathrm{NaCl}$. After three consecutive washings with the same buffer containing $0.1 \%$ Tween 20 , the membrane was incubated with 1:3,000 diluted goat anti-rabbit or anti-mouse $\operatorname{IgG}$ conjugated with alkaline phosphatase (Organon Teknika-Cappel, Durham, NC) for $1 \mathrm{~h}$ at room temperature, washed three times, and incubated with 5-bromo4-chloro-3-indolyl phosphate $(0.15 \mathrm{mg} / \mathrm{ml})$ and nitroblue tetrazolium $(0.30 \mathrm{mg} / \mathrm{ml})$ solution (GIBCO BRL, Gaithersburg, MD) in a buffer solution containing $0.1 \mathrm{M}$ Tris- $\mathrm{HCl}(\mathrm{pH} 9.5), 0.1 \mathrm{M} \mathrm{NaCl}$, and $50 \mathrm{mM}$ $\mathrm{MgCl}_{2}$ until specific bands became clear.

Immunohistochemistry. For indirect immunohistochemical staining, sections cut $2 \mu \mathrm{m}$ thick were mounted on slides coated with 3-aminopropyltriethoxy silane (Sigma Chemical Co.), deparaffinized, rehydrated in distilled water, and incubated with Pronase $(0.5 \mathrm{mg} / \mathrm{ml}$; DAKO A/S, Glostrup, Denmark) for $15 \mathrm{~min}$ at room temperature in a buffer solution containing $0.05 \mathrm{M}$ Tris- $\mathrm{HCl}(\mathrm{pH} 7.2)$ and $0.1 \mathrm{M}$ $\mathrm{NaCl}$. The sections were washed with PBS containing $0.05 \%$ Tween, blocked in $4 \%$ skim milk for $2 \mathrm{~h}$, and subsequently incubated with anti-AGE mouse monoclonal $\mathrm{IgG}(2.0 \mu \mathrm{g} / \mathrm{ml})$, anti-AGE polyclonal rabbit $\operatorname{IgG}(10 \mu \mathrm{g} / \mathrm{ml})$, antipentosidine rabbit IgG $(20 \mu \mathrm{g} / \mathrm{ml})$, antipyrraline mouse monoclonal $\mathrm{IgG}(10 \mu \mathrm{g} / \mathrm{ml})$, anti-MDA mouse monoclonal IgG $(20 \mu \mathrm{g} / \mathrm{ml})$, or 1:400 diluted anticollagen type III, IV, V, or VI goat IgG overnight in humid chambers at room temperature. The sections incubated with anti-AGE mouse monoclonal, anti-AGE rabbit polyclonal, or anticollagen goat IgG were washed and incubated with 1:100 diluted goat anti-rabbit, goat anti-mouse, or rabbit antigoat $\mathrm{IgG}$ conjugated with peroxidase (DAKO A/S), respectively, for $2 \mathrm{~h}$ at room temperature, followed by detection with 3,3'-diaminobenzidine solution containing $0.003 \% \mathrm{H}_{2} \mathrm{O}_{2}$. For detection of pentosidine, pyrraline, and MDA, the sections were incubated with biotinylated goat anti-mouse $\mathrm{IgG}$, followed by incubation with peroxidase-conjugated streptavidin, using a kit (Histofine SAB-PO; Nichirei, Tokyo, Japan). Competition experiments to confirm the specificity of immunostaining were performed with anti-AGE mouse monoclonal, anti-AGE rabbit polyclonal, antipentosidine rabbit, an-

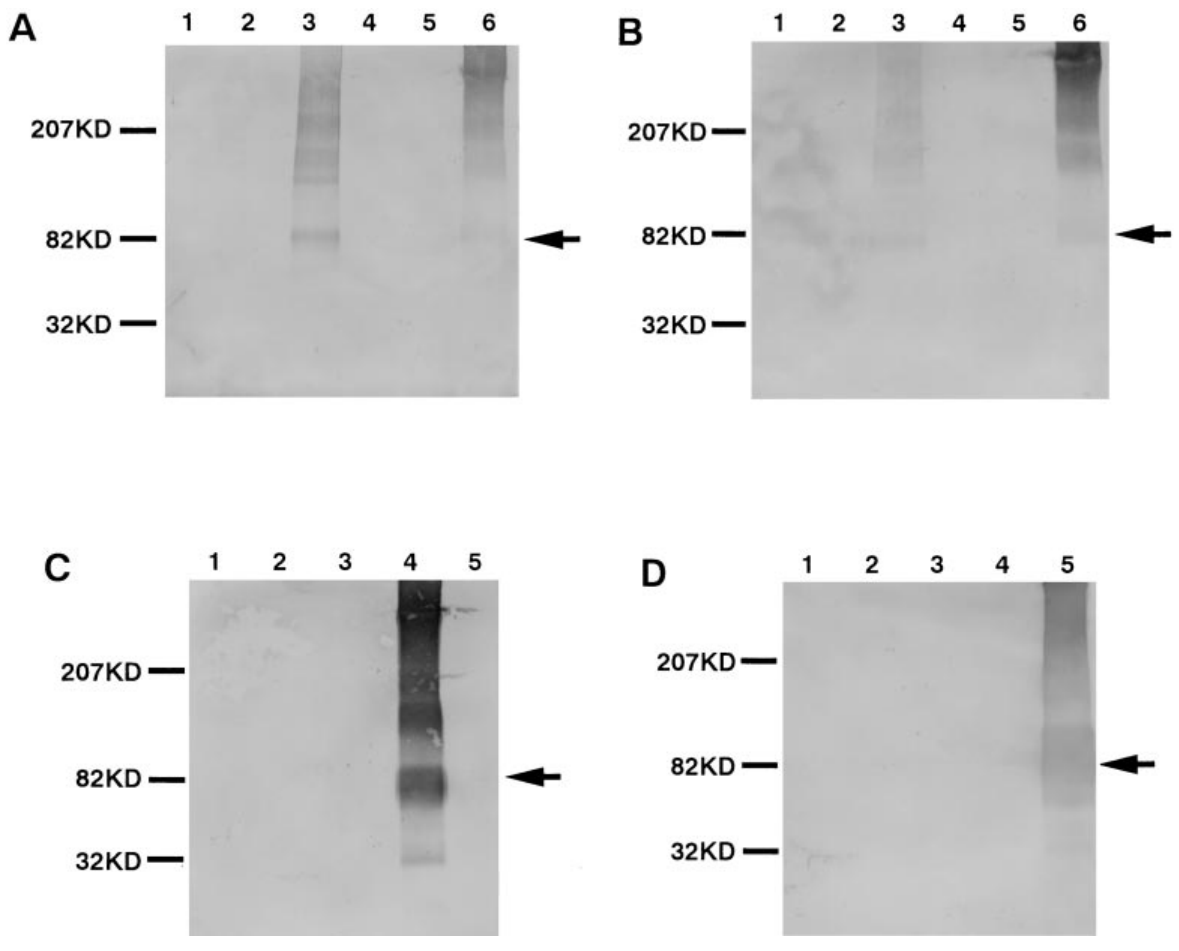

Figure 2. Characterization of antibodies against AGEs used in this study. The samples were resolved by 5-20\% gradient SDS-PAGE, followed by Western blotting using anti-AGE mouse monoclonal IgG $(A)$, anti-AGE rabbit $\operatorname{IgG}(B)$, antipentosidine rabbit $\operatorname{IgG}(C)$, or antipyrraline mouse monoclonal $\operatorname{IgG}(D)$. Lane 1, normal BSA; lane 2, Amadori-BSA; lane 3, CML-BSA; lane 4 , pentosidine-BSA; lane 5, pyrralineBSA; and lane 6, AGE-BSA. The samples were prepared as described in Methods. The position of BSA (arrows) and migration of standard proteins are indicated. Note that anti-AGE mouse monoclonal, anti-AGE rabbit, antipentosidine rabbit, and antipyrraline mouse monoclonal $\mathrm{IgG}$ specifically recognize CML, CML and another unknown AGE structure(s) than pentosidine and pyrraline, pentosidine, and pyrraline, respectively. 
Table II. Summary of Immunostaining for AGEs in Normal and Diabetic Subjects without Nephropathy, and in Patients with IgA Glomerulonephritis and MCNS

\begin{tabular}{|c|c|c|c|c|}
\hline & Mesangial area & Capillary wall & Interstitium & Tubule \\
\hline Pentosidine & $-*$ or $\pm^{\ddagger}$ & - & \pm & + \\
\hline Pyrraline & - & - & + & - \\
\hline CML & $-*$ or $\pm^{\ddagger}$ & - & - & + \\
\hline AGE structures ${ }^{\S}$ & $-*$ or $\pm^{\ddagger}$ & - & \pm & + \\
\hline
\end{tabular}

-, None; \pm , weakly positive; + , strongly positive. *Normal and diabetic subjects without nephropathy, and patients with MCNS. ${ }^{*}$ Patients with IgA nephropathy. ${ }^{\S}$ Recognized by anti-AGE rabbit IgG.

tipyrraline mouse monoclonal, or anti-MDA mouse monoclonal IgG, which had been preincubated with an excess of CML-, AGE-, pentosidine-, pyrraline-, or MDA-BSA, respectively, for $4 \mathrm{~h}$ at $37^{\circ} \mathrm{C}$. Nonimmune rabbit or mouse $\mathrm{IgG}$ was used as a negative control. Immunostaining was evaluated independently for intensity and distribution by three observers.

\section{Results}

Characterization of antibodies against AGEs. On immunoblot analysis (Fig. 2), the four antibodies used in this study recognized distinct AGE structures. Both anti-AGE mouse $\mathrm{mAb}$ (Fig. $2 A$ ) and anti-AGE rabbit polyclonal antibody (Fig. 2 B) reacted with in vitro-prepared AGE proteins such as AGEBSA (lane 6), but not with BSA (lane 1) or with Amadori compound (lane 2). However, the AGE structures recognized by the two antibodies were not identical. Anti-AGE mouse $\mathrm{mAb}$ recognized CML-BSA (lane 3), but not pentosidine(lane 4) or pyrraline-BSA (lane 5). Its reactivity with AGEBSA was abolished completely after preincubation with an excess of either CML- or AGE-BSA (data not shown). Thus, the recognized epitope structure is specifically CML, in agreement with previous observations $(38,39)$. The anti-AGE rabbit polyclonal antibody also reacted with proteins modified with CML but not with those modified with pentosidine or pyrraline (Fig. 2 B). However, in contrast with mouse mAb, the rabbit polyclonal antibody's reactivity with AGE-BSA was not abolished completely after preincubation with an excess of CML-BSA (data not shown). Thus, this antibody recognizes both CML, in agreement with previous observations of Reddy et al. (40), and another unknown AGE structure(s) different from pentosidine and pyrraline. No immunoreaction was detected with nonimmune mouse or rabbit IgG.
As shown in Fig. $2 C$, the antipentosidine antibody reacted with pentosidine-BSA (lane 4), but not with BSA (lane 1), Amadori compound (lane 2), CML- (lane 3), or pyrraline-BSA (lane 5). Thus, it recognizes specifically pentosidine. By contrast, as illustrated in Fig. $2 \mathrm{D}$, the antipyrraline antibody recognized specifically pyrraline-BSA (lane 5), but not CML(lane 3 ) or pentosidine-BSA (lane 4 ). The immunoreactivity of the antipentosidine and the antipyrraline antibodies was abolished completely after preincubation with an excess of pentosidine or pyrraline, respectively (data not shown), demonstrating the high specificity of these antibodies. These four antibodies were used in the subsequent immunohistochemical study.

Immunohistochemical detection of AGEs in normal subjects, in patients with diabetes but without nephropathy, and in patients with IgA nephropathy or MCNS. Results of AGE immunostaining in renal tissues from normal and diabetic subjects without nephropathy and from patients with IgA nephropathy and MCNS are summarized in Table II. The antiAGE monoclonal, anti-AGE polyclonal, and antipentosidine antibodies did not stain the glomeruli (illustrated for antiAGE mAb in Fig. $3 A$ ) except those with IgA nephropathy, in which a faint staining was observed in the expanded mesangial area (illustrated for anti-AGE $\mathrm{mAb}$ in Fig. $3 \mathrm{~B}$ ). The antipyrraline antibody did not react with the glomeruli.

Proximal renal tubular cells were immunostained with antiAGE monoclonal, anti-AGE polyclonal, and antipentosidine antibodies. Immunostaining with antipyrraline was only faint in renal tubular cells. By contrast, interstitial immunostaining was strong with antipyrraline antibody, but moderate or faint with anti-AGE monoclonal, anti-AGE polyclonal, and antipentosidine antibodies, respectively.

Immunohistochemical detection of AGEs in patients with early $D N$. Early DN is characterized by an expanded mesangial matrix and a thickened capillary wall. Results of AGE immunostaining in renal tissues from patients with early DN are summarized in Table III. Glomeruli reacted with anti-AGE monoclonal (Fig. $3 \mathrm{C}$ ), antipentosidine (Fig. $3 \mathrm{D}$ ), and antiAGE polyclonal antibody (Fig. $3 F$ ). Immunostaining was observed mainly in the expanded mesangial area and in capillary walls (illustrated for anti-AGE rabbit antibody in Fig. $3 G$ ). By contrast, pyrraline immunoreactivity was only faint (Fig. $3 E$ ).

Proximal renal tubular cells were immunostained with antiAGE monoclonal, anti-AGE polyclonal, and antipentosidine antibodies (see also Fig. $5 \mathrm{~B}$ ). By contrast, immunostaining with antipyrraline antibody was very weak (see also Fig. $5 A$ ). In the renal interstitium, immunostaining was strong with antipyrraline antibody, mild with antipentosidine antibody, and

Table III. Summary of Immunostaining for AGEs in DN

\begin{tabular}{|c|c|c|c|c|c|c|c|}
\hline & \multicolumn{4}{|c|}{ Early stage } & \multicolumn{3}{|c|}{ Advanced stage } \\
\hline & Mesangial area & Capillary wall & Interstitium & Tubule & Nodular lesion & Ischemic crescent* & Arterial wall ${ }^{\ddagger}$ \\
\hline Pentosidine & + & + & \pm & + & + & + & + \\
\hline Pyrraline & \pm & - & + & - & - & + & + \\
\hline CML & + & \pm & - & + & + & + & + \\
\hline AGE structures ${ }^{\S}$ & + & + & \pm & + & + & + & + \\
\hline
\end{tabular}

- , None; \pm , weakly positive; + , strongly positive. *Observed in the Bowman space of glomeruli. ${ }^{*}$ Thickening intima and perivascular sclerosed lesion. ${ }^{\S}$ Recognized by anti-AGE rabbit IgG. 

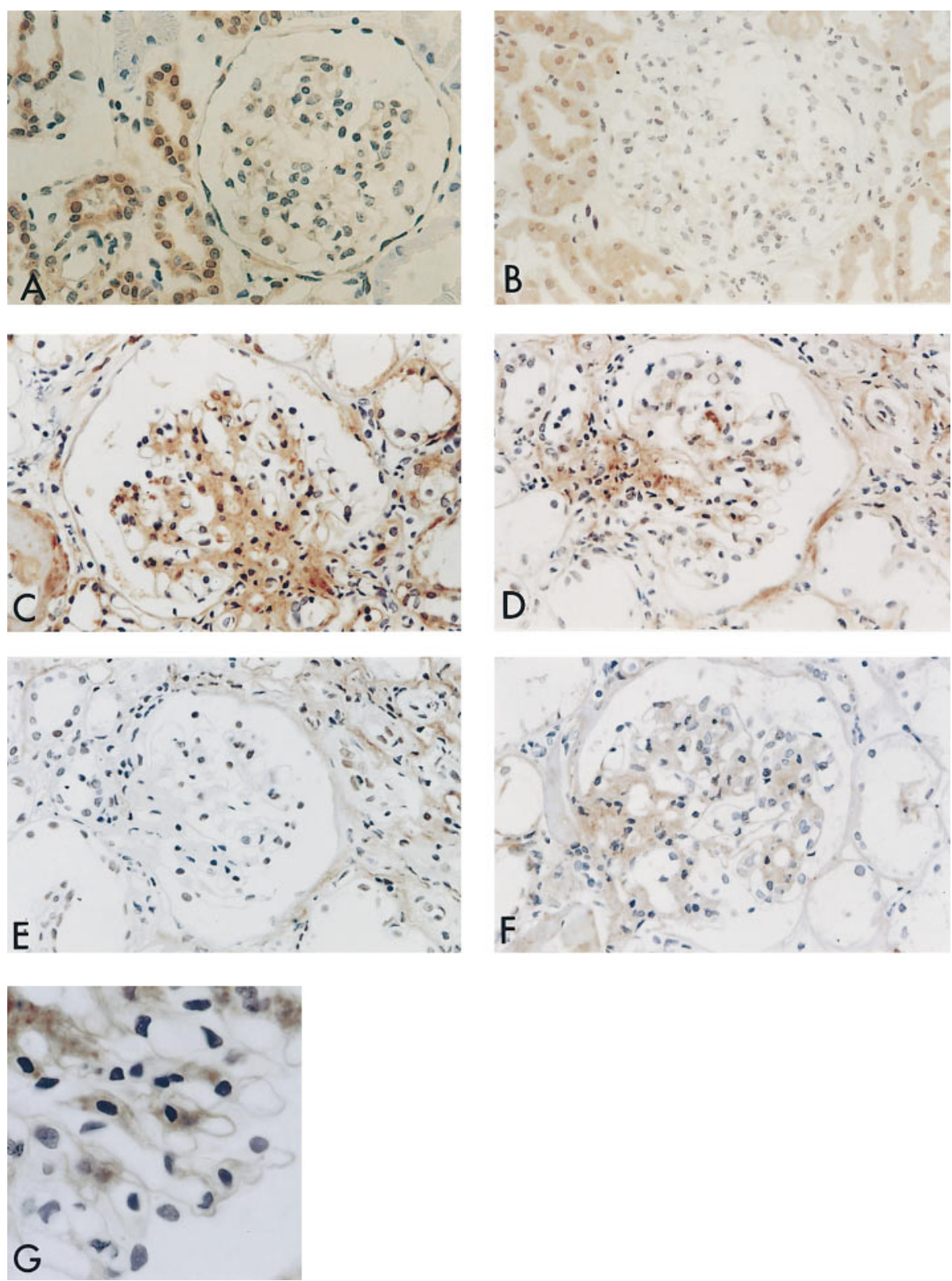

Figure 3. Immunohistochemical detection of AGEs in the expanded mesangial area and capillary walls of the glomeruli from early stage DN. Renal tissue specimens from a 37-yr-old male patient with MCNS $(A)$, a 60-yr-old male patient with IgA nephropathy $(B)$, and a 68-yr-old NIDDM male patient with normal renal function and macroalbuminuria $(C-G)$ were immunostained with anti-AGE $\mathrm{mAb}(A-C)$, antipentosidine antibody $(D)$, antipyrraline antibody $(E)$, or anti-AGE antibody $(F$ and $G)$. The nuclei were counterstained with Meyer's hematoxylin. CML staining was positive in the expanded mesangial area of patients with early $\mathrm{DN}(C)$, whereas it was absent in the mesangial area of patients with MCNS $(A)$ and weak in the expanded mesangial area of patients with IgA nephropathy $(B)$. The staining for pentosidine and the epitope structures of anti-AGE rabbit IgG was positive in the expanded mesangial area and capillary walls $(D, F$ and $G)$. Pyrraline staining was faint in glomeruli (E). $A-F, \times 400 ; G, \times 1,000$. weak with anti-AGE mAb. Immunostaining was specific, as demonstrated by its complete inhibition in the presence of an excess of competitors (data not shown). No immunoreaction was observed with nonimmune mouse or rabbit IgG.

Immunohistochemical detection of AGEs in patients with advanced DN. Advanced DN is characterized by nodular deposits. Results of AGE immunostaining in renal tissues from patients with advanced DN are summarized in Table III. Nodular lesions within the glomeruli were strongly immunostained by anti-AGE monoclonal (Fig. $4 \mathrm{~A}$ ), antipentosidine (Fig. $4 \mathrm{~B}$ ), and anti-AGE rabbit polyclonal antibodies, but only faintly with antipyrraline antibody (Fig. $4 C$ ). The renal tubular cells were immunostained with anti-AGE monoclonal, anti-AGE polyclonal, and antipentosidine antibodies. In the interstitium, the immunostaining was strong with antipyrraline and antipentosidine antibodies. All antibodies, including antipyrraline, reacted predominantly with the thickened intima of arteries with perivascular sclerosis (Fig. 4, $D-F$ ) and with the ischemic crescent observed in the Bowman space of glomeruli (Fig. 4, $G$ and $H$ ).

AGE localization and the distribution of collagen types. The uneven distribution of the various AGE structures in the diabetic kidney might be related to the heterogeneous distribution within the kidney of the various types of collagen. Thus, the distribution of each AGE structure was compared with those of type III, IV, V, and VI collagens. The distribution pattern of collagens was consistent with that reported by others $(41,42)$. It is of note that the distribution of pyrraline coincides with type III collagen: both were absent within normal and diabetic (Fig. 5, $A$ and $C$ ) glomeruli, weakly present in glomerular nodular lesions (compare Fig. $5 F$ with Fig. $4 C$ ), and strikingly present in the interstitium (Fig. 5, $A$ and $C$ ) and in the ischemic crescent within the Bowman space of glomeruli (compare Fig. $5 F$ with Fig. $4 H$ ). By contrast, no such association was ob- 

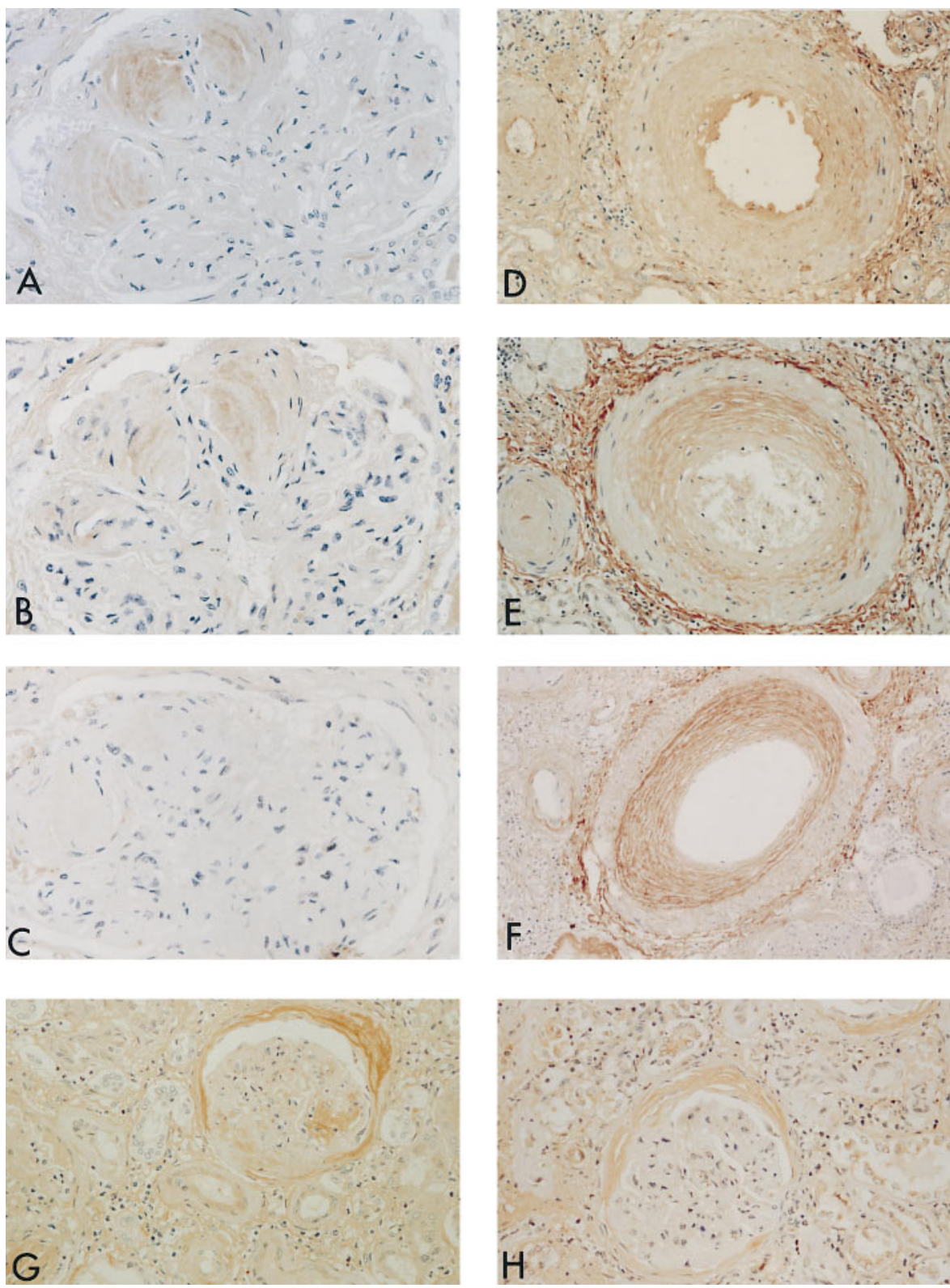
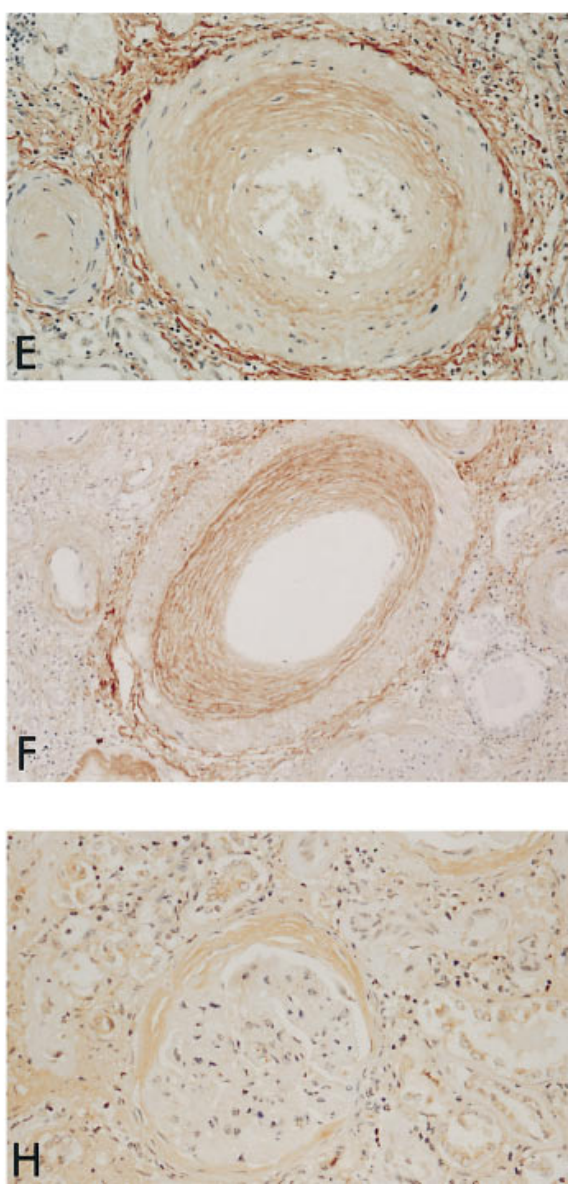

Figure 4. Immunohistochemical detection of AGEs in nodular lesions $(A-C)$, arterial walls $(D-F)$, and the ischemic crescent in sclerosed glomeruli $(G$ and $H$ ) of renal tissues from advanced stage $\mathrm{DN}$. A renal tissue specimen from a 69-yr-old NIDDM male patient with end-stage renal failure was immunostained with anti-AGE $\mathrm{mAb}$ ( $A$ and $D)$, antipentosidine antibody $(B, E$, and $G)$, or antipyrraline antibody $(C, F$, and $H$ ). The nuclei were counterstained with Meyer's hematoxylin. The staining for pentosidine and CML was positive in nodular lesions, and their staining patterns were patchy $(A, B$, and $G)$. Pyrraline staining was faint in nodular lesions, but positive in the ischemic crescent in the Bowman space $(C$ and $H$ ). All the AGE structures examined were stained positive in the thickening intima of arterial walls and perivascular sclerosed lesion $(D, E$, and $F) . A-C, \times 400$; $D-H, \times 200$. served for pentosidine or CML and type III, IV, V, or VI collagens (exemplified for CML in Fig. $5 B$, for type IV collagen in Fig. 5, $D$ and $G$, and for type VI collagen in Fig. 5, $E$ and $H$ ).

Immunohistochemical detection of lipid peroxidation prod- ucts in advanced DN. AGE products such as pentosidine and CML can be derived from both glycation and oxidation of proteins (9-12). The independent effect of local oxidative stress in their genesis is now evaluated by the immunohistochemical lo-

Table IV. Summary of Immunostaining for Collagens in DN

\begin{tabular}{|c|c|c|c|c|c|c|}
\hline & \multicolumn{3}{|c|}{ Early stage } & \multicolumn{3}{|c|}{ Advanced stage } \\
\hline & Mesangial area & Capillary wall & Interstitium & Nodular lesion & Ischemic crescent* & Arterial wall \\
\hline Type III & - & - & + & - & + & + \\
\hline Type IV & + & + & \pm & \pm & \pm & + \\
\hline Type V & + & \pm & \pm & + & \pm & + \\
\hline Type VI & + & \pm & \pm & + & \pm & + \\
\hline
\end{tabular}

-, None; \pm , weakly positive; + , strongly positive. *Observed in the Bowman space of glomeruli. ${ }^{\ddagger}$ Thickening intima and perivascular sclerosed lesion. 

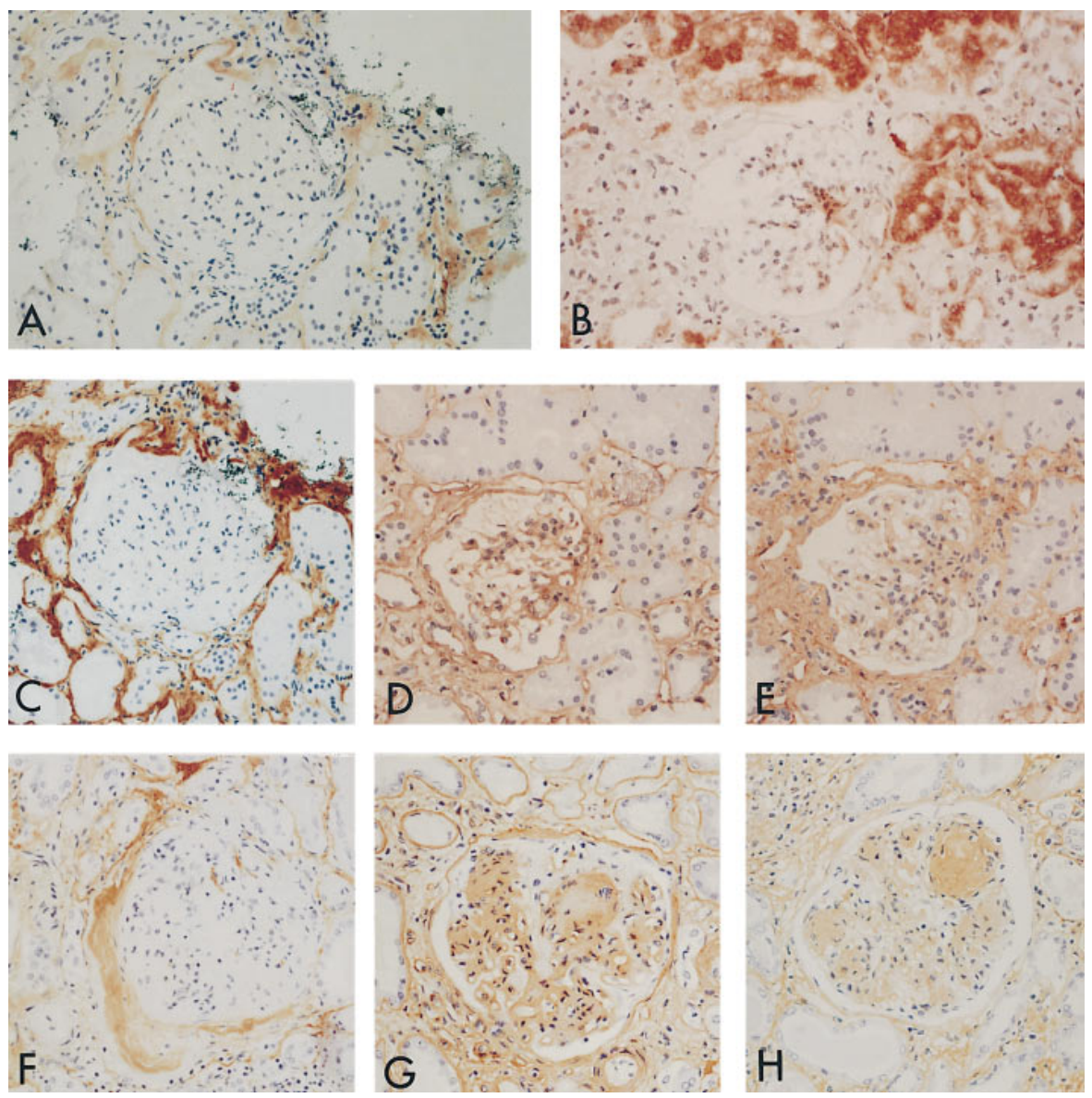

Figure 5. Comparison of immunohistochemical localization between AGEs and collagens in DN. A renal tissue specimen from a 58-yr-old NIDDM male patient with normal renal function and macroalbuminuria $(A-E)$ or from a 69-yr-old NIDDM male patient with end-stage renal failure $(F-H)$ was immunostained with antipyrraline antibody $(A)$, anti-AGE $\mathrm{mAb}(B)$, or anti-type III ( $C$ and $F$ ), IV ( $D$ and $G$ ), or VI $(E$ and $H)$ collagen antibodies. The nuclei were counterstained with Meyer's hematoxylin. The distribution of type III collagen $(C$ and $F$ ) was identical to pyrraline ( $A$, and see Fig. $4 H$ ): absent in glomeruli, faint in nodular lesions, but positive in the interstitium and the ischemic crescent. Type IV and VI collagens were stained positive in the expanded mesangial area $(D$ and $E$ ), capillary walls ( $D$ and $E$ ), and nodular lesions $(G$ and $H) . A-H, \times 200$. calization of a lipid peroxidation product, MDA, whose formation is linked closely to oxidation.

As shown in Fig. $6 \mathrm{~A}$, the anti-MDA mouse mAb reacted with MDA-BSA (lane 5), but not with BSA (lane 1), Amadori compound (lane 2), CML- (lane 3), or pentosidine-BSA (lane 5 ). Thus, it recognizes specifically MDA and does not crossreact with AGEs. Its immunoreactivity was abolished completely after preincubation with an excess of MDA-BSA (data not shown).

Immunostaining with anti-MDA antibody was positive in the expanded mesangial area in early DN (Fig. $6 B$ ), in nodular lesions in advanced DN (Fig. $6 C$ ), and in the thickened intima of arteries with perivascular sclerosis (Fig. $6 \mathrm{D}$ ). Immunostaining was abolished in the presence of an excess of competitor (data not shown), indicating specific immunostaining. The anti-MDA antibody did not react with the glomeruli from normal or diabetic subjects without nephropathy. The colocalization of AGEs (Fig. 3, $C$ and $D$, and Fig. 4, $A$ and $B$ ) and lipid peroxidation products (Fig. 6, $B$ and $C$ ) in the expanded mesangial area and nodular lesions in DN strongly implicates local oxidative stress in their genesis.

\section{Discussion}

This study documents for the first time the distribution pattern of various AGE epitopes in the diabetic kidney and casts some light on their genesis.

$\mathrm{DN}$ is characterized by the accumulation of CML and pen- tosidine within the glomeruli. Deposits are identified by the anti-AGE $\mathrm{mAb}$, which specifically recognizes CML, by the rabbit polyclonal anti-AGE antibody, which recognizes not only CML but also an as yet unidentified AGE epitope, and by the antipentosidine antibody. In the early stage of DN, CML and pentosidine are localized in the expanded mesangial area and in glomerular capillary walls. In the advanced stage, they are localized in glomerular nodular lesions. Interestingly, pyrraline, another AGE structure, is not found in the glomeruli. Neither CML nor pentosidine accumulates outside the glomeruli, in sharp contrast with pyrraline.

This pattern is specific for DN: CML and pentosidine (as well as pyrraline) are absent in the glomeruli from normal kidneys, from IgA nephropathy or MCNS kidneys, and from kidneys of diabetic patients without clinical nephropathy. Why do CML and pentosidine, but not pyrraline, accumulate in DN glomeruli? Both AGE products might be associated preferentially with a specific collagen type. Indeed, the distribution of the various collagen types is heterogeneous in the kidney. However, comparison of AGE immunolocalization patterns with collagen types III-VI discloses an association only between pyrraline and type III collagen within diabetic and normal kidneys: both are absent from glomeruli and present in the interstitium. By contrast, CML and pentosidine are not associated with a single collagen type. Type IV, V, and VI collagens are more evenly distributed, and are present in the diabetic mesangial matrix and diabetic nodular lesions. Type $\mathrm{V}$ and especially type VI collagens are increased significantly in diabe- 


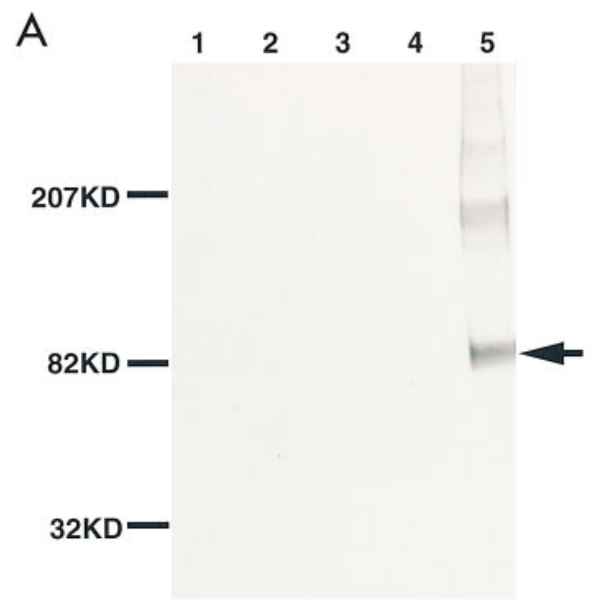

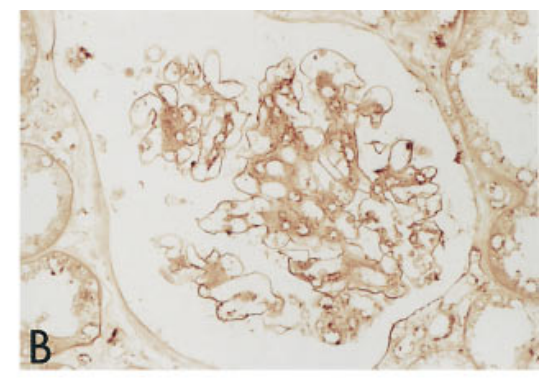
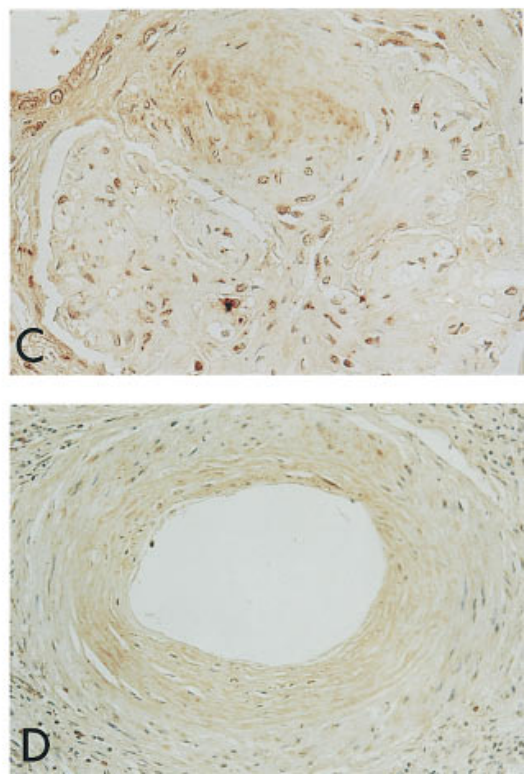

Figure 6. (A) Characterization of antiMDA antibody. The samples were resolved by $5-20 \%$ gradient SDS-PAGE, followed by Western blotting using anti-MDA antibody. Lane 1, normal BSA; lane 2, Amadori-BSA; lane 3, CML-BSA; lane 4, pentosidine-BSA; and lane 5, MDA-BSA. The samples were prepared as described in Methods. The position of BSA (arrow) and migration of standard proteins are indicated. Note that anti-MDA mouse monoclonal IgG specifically recognizes MDA, but not pentosidine or CML. $(B-D)$ Immunohistochemical detection of MDA in DN. Renal tissue specimens from a 63-yr-old NIDDM male patient with normal renal function and macroalbuminuria $(B)$ or a 69-yr-old NIDDM male patient with endstage renal failure ( $C$ and $D$ ) were immunostained with anti-MDA antibody. Immunostaining with anti-MDA antibody was positive in the expanded mesangial area in early $\mathrm{DN}(B)$, in nodular lesions in advanced DN $(C)$, and in the thickened intima of arteries with perivascular sclerosis (D). $B$ and $C, \times 400 ; D, \times 200$. tes compared with normal subjects, contributing to mesangial expansion in DN (41-43). Thus, collagen distribution does not account for the preferential glomerular accumulation of CML and pentosidine.

Alternatively, CML and pentosidine might accumulate specifically in diabetic glomeruli for local reasons. AGEs are formed by a nonenzymatic reaction between sugar and longlived matrix proteins. Although glucose is thought to be a major source of AGEs, it has been demonstrated recently that ascorbate, ribose, fructose, and other carbohydrates may contribute to the genesis of CML (44), pentosidine $(30,45)$, and pyrraline (46). More important, however, is the demonstration that AGE formation, at least of CML and pentosidine, depends also on oxidative processes. Wolff and colleagues have demonstrated that reducing sugars can autoxidize by metalcatalyzed oxidative processes, and generate $\mathrm{H}_{2} \mathrm{O}_{2}$ reactive oxygen intermediates and ketoaldehydes, which contribute to chromo- and fluorophoric alterations of proteins $(47,48)$. As shown by Baynes and colleagues, oxidation is essential for the formation of CML and pentosidine (9, 44, 45). Thus, some AGEs are produced by combined processes of glycation and oxidation (thereby termed glycoxidation). Each AGE structure has its own formation mechanism and thus its own dependence on oxidative stress. The similarity of the pattern of pyrraline in normal and diseased renal tissues suggests that pyrraline deposition is rather independent from high oxidative stress. By contrast, the presence of pentosidine and especially CML at sites characteristic of the disease, and their absence in normal kidney, suggest that their formation is catalyzed by a local oxidative stress. The detection of MDA, a glycation-independent lipid peroxidation product, at the glomerular sites of pentosidine and CML accumulation provides suggestive evidence of a local oxidative stress. It can be hypothesized that reactive oxygen species might be released within diabetic glomeruli as a result of a reaction between AGE epitopes and the cell surface AGE receptor (49). Indeed, this reaction is known to upregulate oxidative stress response genes such as nuclear factor $\mathrm{\kappa B}$ and hemeoxygenase (50) and release oxygen radicals (49) which, in turn, might engender lipid peroxidation products such as MDA. Alternatively, the presence of MDA together with pentosidine and CML suggests that a local oxidative stress contributes to their in situ generation. In the kidney, experimental evidence supports a definite role for oxidative radical generation in the development of glomerular lesions (51, 52). Taken together, our data are compatible with the hypothesis that in DN, local intraglomerular and vascular deposition of CML and pentosidine result not only from high levels of carbohydrate precursors but also from a local condition of oxidative stress.

These observations are potentially of great interest. First, they provide first-hand evidence that CML and pentosidine are markers of both protein glycation and oxidation. Second, they raise the possibility that prevention of DN should rely not only on an adequate control of blood glucose levels but also on the prevention of local oxidative stress.

Accumulation of pentosidine and CML within proximal tu- 
bular cells of normal and diabetic kidneys probably reflects the tubular reabsorption of free-form pentosidine and CML. Both compounds have been identified in the plasma and the urine $(5,32)$. Furthermore, pentosidine concentration is markedly elevated in uremic plasma (32). Pentosidine probably originates from dietary sources (32) and from the degradation of AGE-modified matrix tissue proteins. The molecular masses of free-form pentosidine (379 D) and CML (204 D) allow complete filtration through the capillary GBM. Together with our recent observation that pentosidine is transiently detectable within proximal renal tubular cells of rats after an intravenous load of synthetic free-form pentosidine (53), these immunohistochemical results support the hypothesis that circulating freeform pentosidine and CML are filtered continuously through the glomerulus and partially reabsorbed by the proximal renal tubule (54).

The segmental nature of the staining with anti-AGE antibody may have to do with a novel, enzymatic mechanism of AGE formation, based on glycolaldehyde formation upon myeloperoxidase-mediated Strecker degradation of serine (55). Thus, this additional mechanism of CML formation strongly supports the concept of localized oxidative stress, whereby it is now clear that CML in the diabetic kidney may originate from sources other than glycoxidation alone.

In conclusion, DN is associated with a specific accumulation within the glomeruli of CML, pentosidine, and an as yet undefined epitope recognized by an anti-AGE polyclonal rabbit antibody. They appear to be formed locally in association with type IV-VI collagens not only as a result of glycation but also a local oxidative stress demonstrated by the coincidental presence of MDA. By contrast, pyrraline accumulates mainly on collagen type III fibers in the interstitium of both normal and diabetic kidneys.

\section{Acknowledgments}

We thank Prof. Shuichi Shigematsu for critically reviewing this manuscript.

This study was supported by a grant from the Research for the Future Program of the Japan Society for the Promotion of Science (96L00303).

\section{References}

1. 1995. Effect of intensive therapy on the development and progression of diabetic nephropathy in the Diabetes Control and Complications Trial. The Diabetes Control and Complications (DCCT) Research Group. Kidney Int. 47: 1703-1720.

2. Bangstad, H.J., R. Østerby, K. Dahl-Jørgensen, K.J. Berg, A. Hartmann, and K.F. Hanssen. 1994. Improvement of blood glucose control in IDDM patients retards the progression of morphological changes in early diabetic nephropathy. Diabetologia. 37:483-490.

3. Brownlee, M., A. Cerami, and H. Vlassara. 1988. Advanced glycosylation end products in tissue and the biochemical basis of diabetic complications. $N$. Engl. J. Med. 318:1315-1321.

4. Dyer, D.G., J.A. Dunn, S.R. Thorpe, K.E. Bailie, T.J. Lyons, D.R. McCance, and J.W. Baynes. 1993. Accumulation of Maillard reaction products in skin collagen in diabetes and aging. J. Clin. Invest. 91:2463-2469.

5. Ahmed, M.U., S.R. Thorpe, and J.W. Baynes. 1986. Identification of $N^{\epsilon}$-carboxymethyllysine as a degradation product of fructoselysine in glycated protein. J. Biol. Chem. 261:4889-4894.

6. Sell, D.R., and V.M. Monnier. 1989. Structure elucidation of a senescence cross-link from human extracellular matrix. J. Biol. Chem. 264:2159721602.

7. Njoroge, F.G., L.M. Sayre, and V.M. Monnier. 1987. Detection of glucose-derived pyrrole compounds during Maillard reaction under physiological conditions. Carbohydr. Res. 167:211-220.

8. Baynes, J.W., and V.M. Monnier. 1989. The Maillard reaction in aging, diabetes and nutrition. Prog. Clin. Biol. Res. 304:1-410

9. Baynes, J.W. 1991. Perspectives in diabetes: role of oxidative stress in development of complications in diabetes. Diabetes. 40:405-412.

10. Wells-Knecht, K.J., D.V. Zyzak, J.E. Litchfield, S.R. Thorpe, and J.W. Baynes. 1995. Mechanism of autoxidative glycosylation: identification of glyoxal and arabinose as intermediates in the autoxidative modification of proteins by glucose. Biochemistry. 34:3702-3709.

11. Wells-Knecht, M.A., S.R. Thorpe, and J.W. Baynes. 1995. Pathways of formation of glycoxidation products during glycation of collagen. Biochemistry. 34:15134-15141.

12. Glomb, M.A., and V.M. Monnier. 1995. Mechanism of protein modification by glyoxal and glycoaldehyde, reactive intermediates of the Maillard reaction. J. Biol. Chem. 270:10017-10026.

13. Monnier, V.M., V. Vishwanath, K.E. Frank, C.A. Elmets, P. Dauchot, and P.R. Kohn. 1986. Relation between complications of type I diabetes mellitus and collagen-linked fluorescence. N. Engl. J. Med. 314:403-408.

14. Sell, D.R., A. Lapolla, P. Odetti, J. Fogarty, and V.M. Monnier. 1992. Pentosidine formation in skin correlates with severity of complication in individuals with long-standing IDDM. Diabetes. 41:1286-1292.

15. McCance, D.R., D.G. Dyer, J.A. Dunn, K.E. Bailie, S.R. Thorpe, J.W. Baynes, and T.J. Lyons. 1993. Maillard reaction products and their relation to complications in insulin-dependent diabetes mellitus. J. Clin. Invest. 91:2470 2478 .

16. Beisswenger, P.J., L.L. Moore, T. Brinck-Johnsen, and T.J. Curphey. 1993. Increased collagen-linked pentosidine levels and advanced glycosylation end products in early diabetic nephropathy. J. Clin. Invest. 92:212-217.

17. Monnier, V.M., D.R. Sell, R.H. Nagaraj, S. Miyata, S. Grandhee, P. Odetti, and S.A. Ibrahim. 1992. Maillard reaction-mediated molecular damage to extracellular matrix and other tissue proteins in diabetes, aging, and uremia. Diabetes. 41:36-41.

18. Kirstein, M., J. Brett, S. Radoff, S. Ogawa, D. Stern, and H. Vlassara. 1990. Advanced protein glycosylation induces transendothelial human monocyte chemotaxis and secretion of platelet-derived growth factor: role in vascular disease of diabetes and aging. Proc. Natl. Acad. Sci. USA. 87:9010-9014.

19. Vlassara, H., M. Brownlee, K.R. Manogue, C.A. Dinarello, and A. Pasagian. 1988. Cachectin/TNF and IL-1 induced by glucose-modified proteins: role in normal tissue remodeling. Science. 240:1546-1548.

20. Miyata, T., R. Inagi, Y. Iida, M. Sato, N. Yamada, O. Oda, K. Maeda, and H. Seo. 1994. Involvement of $\beta 2$-microglobulin modified with advanced glycation end products in the pathogenesis of hemodialysis-associated amyloidosis. Induction of human monocyte chemotaxis and macrophage secretion of tumor necrosis factor- $\alpha$ and interleukin-1. J. Clin. Invest. 93:521-528.

21. Iida, Y., T. Miyata, R. Inagi, S. Sugiyama, and K. Maeda. 1994. $\beta 2-$ Microglobulin modified with advanced glycation end products induces interleukin-6 from human macrophages: role in the pathogenesis of hemodialysis-associated amyloidosis. Biochem. Biophys. Res. Commun. 201:1235-1241.

22. Miyata, T., Y. Iida, Y. Ueda, T. Shinzato, H. Seo, V.M. Monnier, K. Maeda, and Y. Wada. 1996. Monocyte/macrophage response to $\beta 2$-microglobulin modified with advanced glycation end products. Kidney Int. 49:538-550.

23. Neeper, M., A.M. Schmidt, J. Brett, S.D. Yan, F. Wang, Y.C. Pan, K. Ellison, D. Stern, and A. Shaw. 1992. Cloning and expression of a cell surface receptor for advanced glycosylation end products of proteins. J. Biol. Chem. 267: 14998-15004.

24. Miyata, T., O. Hori, J. Zhang, S.D. Yan, L. Ferran, Y. Iida, and A.M. Schmidt. 1996. The receptor for advanced glycation end products (RAGE) is a central mediator of the interaction of AGE- $\beta 2$ microglobulin with human mononuclear phagocytes via an oxidant-sensitive pathway. J. Clin. Invest. 98: 1088-1094.

25. Skolnik, E.Y., Z. Yang, Z. Makita, S. Radoff, M. Kirstein, and H. Vlassara. 1991. Human and rat mesangial cell receptors for glucose-modified proteins: potential role in kidney tissue remodelling and diabetic nephropathy. $J$. Exp. Med. 174:931-939.

26. Doi, T., H. Vlassara, M. Kirstein, Y. Yamada, G.E. Striker, and L.J. Striker. 1992. Receptor-specific increase in extracellular matrix production in mouse mesangial cells by advanced glycosylation end products is mediated via platelet-derived growth factor. Proc. Natl. Acad. Sci. USA. 89:2873-2877.

27. Brett, J., A.M. Schmidt, S.D. Yan, Y.S. Zou, E. Weidman, D. Pinsky, R. Nowygrod, M. Neeper, C. Przysiecki, A. Shaw, et al. 1993. Survey of the distribution of a newly characterized receptor for advanced glycation end products in tissues. Am. J. Pathol. 143:1699-1712.

28. Soulis-Liparota, T., M. Cooper, D. Papazoglou, B. Clarke, and G. Jerums. 1991. Retardation by aminoguanidine of development of albuminuria, mesangial expansion, and tissue fluorescence in streptozocin-induced diabetic rat. Diabetes. 40:1328-1334.

29. Houglum, K., M. Filip, J.L. Witztum, and M. Chojkier. 1990. Malondialdehyde and 4-hydroxynonenal protein adducts in plasma and liver of rats with iron overload. J. Clin. Invest. 86:1991-1998.

30. Grandhee, S.K., and V.M. Monnier. 1991. Mechanism of formation of the Maillard protein cross-link pentosidine. J. Biol. Chem. 266:11649-11653.

31. Miyata, T., S. Taneda, R. Kawai, Y. Ueda, S. Horiuchi, M. Hara, K Maeda, and V.M. Monnier. 1996. Identification of pentosidine as a native structure for advanced glycation end products in $\beta 2$-microglobulin-containing amy- 
loid fibrils in patients with dialysis-related amyloidosis. Proc. Natl. Acad. Sci. USA. 93:2353-2358.

32. Miyata, T., Y. Ueda, T. Shinzato, Y. Iida, S. Tanaka, K. Kurokawa, C. van Ypersele de Strihou, and K. Maeda. 1996. Accumulation of albumin-linked and free-form pentosidine in the circulation of uremic patients with end-stage renal failure: renal implications in the pathophysiology of pentosidine. J. Am. Soc. Nephrol. 7:1198-1206.

33. Horiuchi, S., N. Araki, and Y. Morino. 1991. Immunochemical approach to characterize advanced glycation end products of the Maillard reaction. $J$. Biol. Chem. 266:7329-7332.

34. Miyata, S., and V.M. Monnier. 1992. Immunohistochemical detection of advanced glycosylation end products in diabetic tissues using monoclonal antibody to pyrraline. J. Clin. Invest. 89:1102-1112.

35. Rosenfeld, M.E., W. Palinski, S.Y. Herttula, S. Butler, and J.L. Witztum. 1990. Distribution of oxidation specific lipid-protein adducts and apolipoprotein B in atherosclerotic lesions of varying severity from WHHL rabbits. Arteriosclerosis. 10:336-349.

36. Palinski, W. S.Y. Herttula, M.E. Rosenfeld, S.W. Butler, S.A. Socher, S. Parthasathy, L.K. Curtiss, and J.L. Witztum. 1990. Antisera and monoclonal antibodies specific for epitopes generated during oxidative modification of low density lipoprotein. Arteriosclerosis. 10:325-335.

37. Miyata, T., O. Oda, R. Inagi, Y. Iida, N. Araki, N. Yamada, S. Horiuchi, N. Taniguchi, K. Maeda, and T. Kinoshita. 1993. ß2-Microglobulin modified with advanced glycation end products is a major component of hemodialysis-associated amyloidosis. J. Clin. Invest. 92:1243-1252.

38. Ikeda, K., T. Higashi, H. Sano, Y. Jinnouchi, M. Yoshida, T. Araki, S. Ueda, and S. Horiuchi. 1996. $N^{\epsilon}$-(carboxymethyl)lisine protein adduct is a major immunological epitope in proteins modified with advanced glycation end products of the Maillard reaction. Biochemistry. 35:8075-8083.

39. Miyata, T., Y. Wada, Z. Cai, Y. Iida, K. Horie, K. Maeda, K. Kurokawa, and C. van Ypersele de Strihou. 1997. Implication of an increased oxidative stress in patients with end-stage renal failure. Kidney Int. 51:1170-1181.

40. Reddy, S., J. Bichler, K.J. Wells-Knecht, S.R. Thorpe, and J.W. Baynes. 1995. $N^{\epsilon}$-(carboxymethyl)lysine is a dominant advanced glycation end product (AGE) antigen in tissue proteins. Biochemistry. 34:10872-10878.

41. Falk, R.J., J.I. Scheinman, S.M. Mauer, and A.F. Michael. 1983. Polyantigenic expansion of basement membrane constituents in diabetic nephropathy. Diabetes. 32(Suppl. 2):34-39.

42. Makino, H., K. Shikhata, J. Wieslander, J. Wada, N. Kashihara, K. Yoshioka, and Z. Ota. 1993. Localization of fibril/microfibril and basement membrane collagens in diabetic glomerulosclerosis in type 2 diabetes. Diabet. Med. 11:304-311.

43. Mohan, P.S., W.G. Carter, and R.G. Spiro. 1990. Occurrence of type VI collagen in extracellular matrix of renal glomeruli and its increase in diabetes. Diabetes. 39:31-37.
44. Dunn, J.A., M.U. Ahmed, M.H. Murtiashaw, J.M. Richardson, M.D. Walla, S.R. Thorpe, and J.W. Baynes. 1990. Reaction of ascorbate with lysine and protein under autoxidizing conditions: formation of $N^{\epsilon}$-(carboxymethyl)lysine by reaction between lysine and products of autoxidation of ascorbate. Biochemistry. 29:10964-10970.

45. Dyer, D.G., J.A. Blackledge, S.R. Thorpe, and J.W. Baynes. 1991. Formation of pentosidine during nonenzymatic browning of protein by glucose: identification of glucose and other carbohydrates as possible precursors of pentosidine in vivo. J. Biol. Chem. 266:11654-11660.

46. Portero-Otin, M., R.H. Nagaraj, and V.M. Monnier. 1995. Chromatographic evidence for pyrraline formation during protein glycation in vitro and in vivo. Biochim. Biophys. Acta. 1247:74-80.

47. Wolff, S.P., and R.T. Dean. 1987. Glucose autoxidation and protein modification. The potential role of 'autoxidative glycosylation' in diabetes. Biochem. J. 245:243-250.

48. Hunt, J.V., R.T. Dean, and S.P. Wolff. 1988. Hydroxyl radical production and autoxidative glycosylation: glucose autoxidation as the cause of protein damage in the experimental glycation model of diabetes mellitus and aging. Biochem. J. 256:205-212.

49. Yan, S.D., A.M. Schmit, G.M. Anderson, J. Zhang, Y.S. Zou, D. Pinsky, and D. Stern. 1994. Enhanced cellular oxidant stress by the interaction of advanced glycation end products with their receptor/binding protein. J. Biol. Chem. 269:9889-9897.

50. Yan, S.D., H. Zhu., J. Fu, S.F. Yan, A. Roher, W.W. Tourtellotte, T. Rajavashisth, X. Chen, G.C. Godman, D. Stern, and A.M. Schmit. 1997. Amyloid- $\beta$ peptide-receptor for advanced glycation endproduct interaction elicits neuronal expression of macrophage-colony stimulating factor: a proinflammatory pathway in Alzheimer disease. Proc. Natl. Acad. Sci. USA. 94:5296-5301.

51. Diamond, J.R. 1992. The role of reactive oxygen species in animal models of glomerular disease. Am. J. Kidney Dis. 3:292-300.

52. Johnson, R.J., D. Lovett, R.I. Lehrer, W.G. Couser, and S.J. Klebanoff 1994. Role of oxidants and proteases in glomerular injury. Kidney Int. 45:352-359.

53. Miyata, T., Y. Ueda, K. Horie, M. Nangaku, S. Tanaka, C. van Ypersele de Strihou, and K. Kurokawa. 1998. Renal catabolism of advanced glycation end products: the fate of pentosidine. Kidney Int. In press.

54. Gugliucci, A., and M. Bendayan. 1996. Renal fate of circulating advanced glycated end products (AGE): evidence for reabsorption and catabolism of AGE-peptides by renal proximal tubular cells. Diabetologia. 39:149-160.

55. Anderson, M.M., S.L. Hazen, F.F. Hsu, and J.W. Heinecke. 1997. Human neutrophils employ the myeloperoxidase-hydrogen peroxide-chloride system to convert hydroxy-amino acids into glycolaldehyde, 2-hydroxypropanol, and acrolein. A mechanism for the generation of highly reactive $\alpha$-hydroxy and $\alpha, \beta$-unsaturated aldehydes by phagocytes at sites of inflammation. J. Clin. Invest. 99:424-432. 